PREHISTORIC ART.1

$\mathrm{N}$ an advancing science like anthropology, it is well to take stock periodically of the material which is so rapidly being accumulated. Mr. Parkyn in this book displays much industry in studying the literature of the subject; but his work must not be taken to be the last word

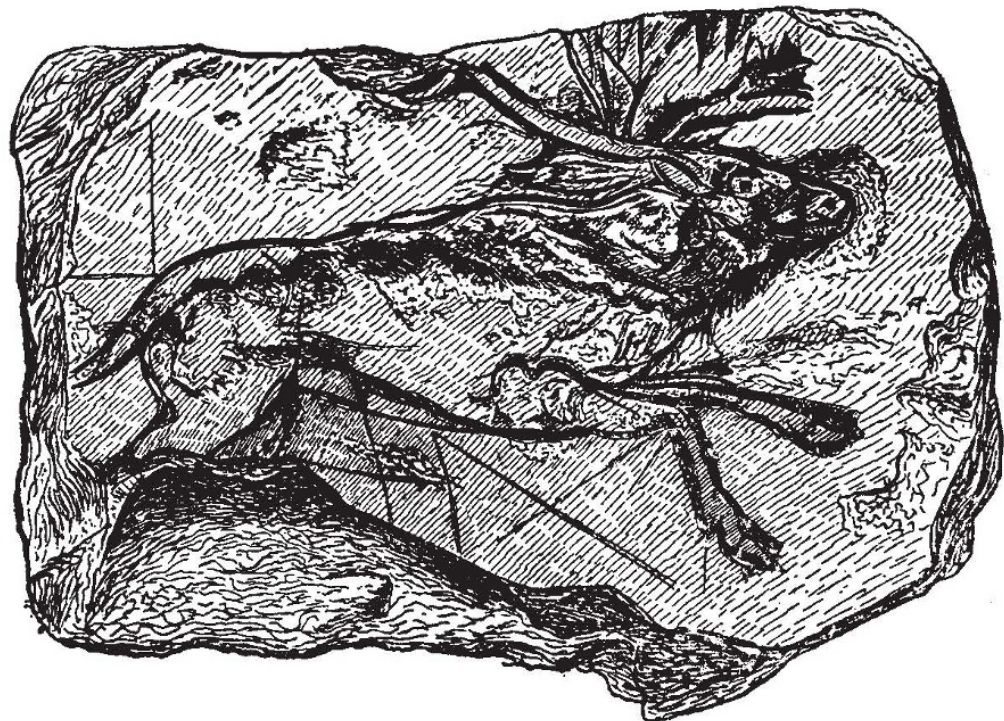

FIG. I.-S. Marcel. Reindeer on schist. (Natural size.) From "An Introduction to the Study of Prehistoric Art."

on the subject, nor does it supply an adequate history of prehistoric art. His survey covers an enormous period, from the Palæolithic Age down to that of Late Keltic ornament, and the pressure on his space in dealing with such a mass of material necessarily forbids detailed investigation of evolution or æsthetics, while his imperfect sense of style and the desire to compress the facts make his book hard reading. At the same time, it is well documented and provided with a number of good illustrations, some of them in colour, and many old friends, which will render it useful to the student if he is prepared to treat it as a "source" book. It may be used with advantage as a supplement to the "Ancient Hunters," by Prof. Sollas, who has described with notable success early man from the physical and ethno-
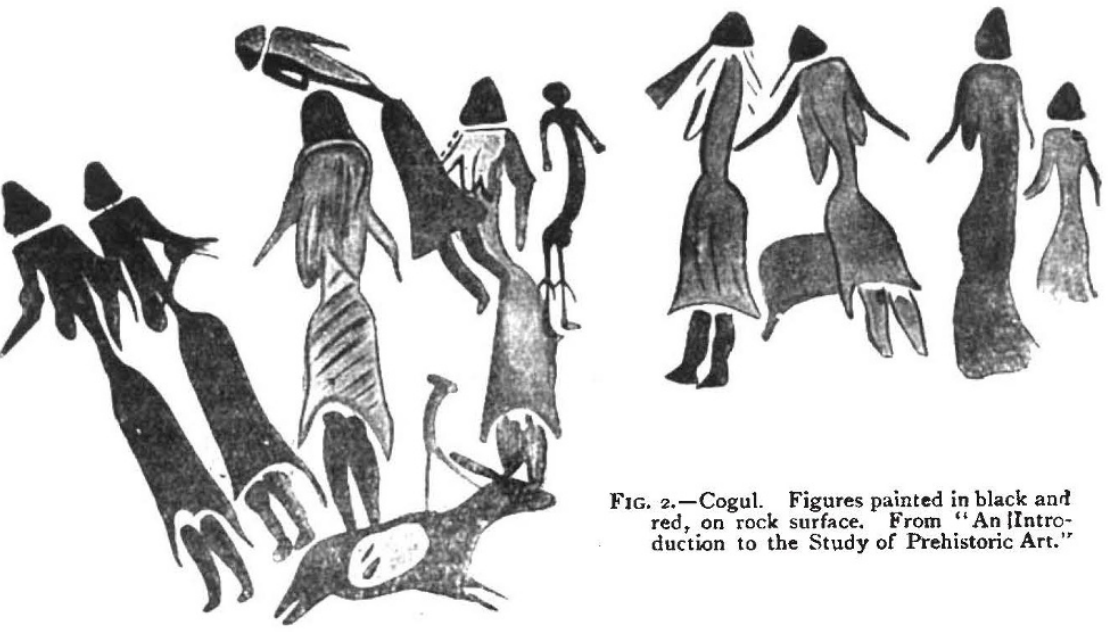
of shrine in which a form of animal or totemistic cult may have been carried on. The human performers are regarded as subordinate to this ritual, whatever form it may have taken, and the object of the cult may have been to promote the fertility of the fauna which supplied their food graphical side.

The account of the cave frescoes, which constitutes the most valuable part of the book, opens up a school of art our knowledge of which starts from the discovery in 1879 , by M. S. de Santuola, 1 "An Introduction to the Study of Prehistoric Art." By E. A. Parkyn. Pp. xviii +349. (London: Longmans, Green and Co., 19r5.) Price ros.6d. net.

NO. 2414 , VOL. 967 of paintings in the now celebrated cave of Altamira a Santilane, near Santander, in north-west Spain. Since then numerous discoveries in the prenean and Dordogne regions and in Spain duce us to an art school, keen observers of the animal life which surrounded the workers, and possessed of admirable skill both in drawing and painting. Mr. Parkyn, except in a summary way, does not discuss the many points of interest suggested by these frescoes. $\mathrm{He}$ believes that the art of sculpture preceded those of engraving and painting, but the materials at present available seem to be insufficient to indicate the seriation or course of evolution of these phases of art production. Another interesting fact is that while the artists represent animal forms with much skill and powers of observation, their delineations of the human form are little better than caricatures, even if it be admitted that some examples represent masked dancers. Again, as at the cave of Combarelles, the paintings occupy the walls, not of the outer dwelling-place, but are found in an interior gallery. These facts have led to the theory that the frescoes adorned the walls of some kind 
break in artistic skill, of which we have at least two instances: the decline in skill in stone-work in the Solutrian period as compared with that of La Madelaine, and the equally remarkable failure in artistic powers of Neolithic as compared with Palæolithic man. In the first case, Mr. Parkyn suggests that the decline was due to the worker finding other fields for his artistic skill in the use of bone and horn instead of stone, and to the growth of the taste for engraving. In the latter case it can only be suggested that it depends on a difference of race and environment, the age of polished stone marking the beginnings of settled life, agriculture, and cattle-raising.

Enough has been said to indicate the value of this book, provided that the reader does not expect from it what it was not intended to supply. The field is still open for a monograph on the art of the Ages of Stone in which the evolution of the crafts of these early workers and the artistic spirit shown in fresco, sculpture, and the working of an intractable material like flint shall receive adequate examination.

\section{THE ORGANISATION OF EMBRYOLOGICAL RESEARCH IN AMERICA.}

WHEN British anatomists come to examine "Contributions to Embryology," 1 which have been issued by the Carnegie Institution of Washington as publications numbers $22 x, 222$, they will be liss than human if they do not feel a twinge of jealousy. Five-and-twenty years ago anatomists in America were British in method and in spirit; they were easy-going, each man following leisurely his own individual bent. Since that time a remarkable change has taken place; the number of laboratories in which the structure and development of the human body are taught and investigated have increased tenfold; the number of investigators has grown in a still greater ratio; in quantity and quality their anatomical proceedings and journals have come to rival those of any country in Europe.

In effecting this transformation the chief credit must be assigned to one man-Franklin P. Mall, for twenty-three years professor of anatomy at the Johns Hopkins University. He planted in Baltimore the methods and aims which he acquired when working in the laboratory of the late Prof. His at Leipzig. By his personal influence and example, by pupils and disciples, and by reason of the inherent excellence of the Leipzig traditions, he has succeeded in Germanising the majority of the dissecting rooms and anatomical laboratories throughout the length and breadth of North America.

The issue of "Contributions to Embryology" marks a new phase in the career of Dr. Mall and the beginning of another period in the history of human anatomy in North America. In I9r3 Dr. Mall issued "A Plea for an Institute of Human Embryology." 2

1 Carnegie Institution of Washington Publications. Nos. 22r, 222. "Contributions to Embryology." Vol. i., No. x. Vol. ii., Nos. 2-6. Vol. üii., Nos. $7-9$.

2 Journal of the American Medical Association, 19r3, vol. 1x., p. 1509 NO. 24I4, VOL. 967
"At present," he wrote, "it seems impossible for the investigator-teachers to make greater progress than is here shown without better organisation, and it is for this reason that I renew the plea of $\mathrm{His}$ for an Institute of Human Embryology. Only in this way can we hope to secure a complete embryologic and scientific basis for human anatomy which, it is being recognised, is in a chaotic state. . . There should be an Institute of Human Embryology just as there is one for Human Palæontology recently founded in Paris by the Prince of Monaco.'

The conception of founding such an institute in North America is Dr. Mall's, but the possibility of its realisation was Mr. Carnegie's. At the close of last year (December, 1914) the trustees of the Carnegie Institution of Washington established a Department of Embryology, appointed Dr. Mall as Director, and gave him an "investigatory staff," which includes some of the leading embryologists of the present day, with all forms of skilled assistants needed in laboratories of such a kind. At present Dr. Mall and his staff are housed in the cheap brick building which forms the Anatomical Department of Johns Hopkins University. The new institution or department of embryology is already at work, and the manner in which it is to fulfil its destiny may be inferred from the high quality of vols. i. and ii. of "Contributions to Embryology."

In vol. i. Dr. Mall gives the results of minute examination of $\mathrm{I} I 7$ specimens where the human ovum had been arrested in the Fallopian tube, and started to develop there in place of passing on to its normal site in the uterus. When the late Mr. Lawson Tait, some thirty years ago, showed that the lives of women who were the subjects of tubal pregnancy could be saved by prompt operation, the condition was supposed to be rare; we now know that it is common, and there is an evergrowing body of evidence which demonstrates that it results from an inflammation of the tube, often venereal in nature. The facts observed by Dr. Mall support the theory of an inflammatory causation. In above 90 per cent. of the cases he found that the embryo was also diseased or arrested in development. For anyone who would continue a research on tubal pregnancy-or who may wish to know the best that can be known of the subject at present-a study of Dr. Mall's records and illustrations is absolutely essential.

In the second volume there are five papers, all of them forming definite and useful additions to our knowledge of the human embryo. Dr. James Crawford Watt describes two very young twin embryos, at a stage of development which has not been recorded before. Prof. Eliot Clarke gives an embryological explanation of a very rare anomaly-a subcutaneous vessel taking the place of the thoracic duct. Dr. Charles R. Essick describes certain transitory cavities which occur in the developing ganglia at the base of the brain. The two remaining papers are devoted to the growth of the human fœtus and to the development and nature of the corpus luteum of the ovary.

In vol. iii. the same high standard is main- 